\title{
Sturge-Weber syndrome with bilateral intracranial calcification
}

\author{
E. BOLTSHAUSER ${ }^{1}$, J. WILSON, AND R. D. HOARE \\ From the Departments of Neurology and Radiology, The Hospital for Sick Children, \\ Great Ormond Street, London
}

SYNOPSIS Four children affected by Sturge-Weber syndrome and demonstrating bilateral intracranial calcification are described, bringing up to 21 the number of similar reported cases. The frequency of bilateral hemisphere involvement in this syndrome is not known, but it might be as high as $15 \%$. If present, neurosurgical intervention is, in our opinion, contraindicated.

The Sturge-Weber syndrome, although a rare condition, has attracted considerable interest, resulting in the accumulation of a very extensive literature. In its classical form the syndrome is characterized by (1) a congenital, usually unilateral, capillary naevus ('port-wine stain') affecting the face, particularly the supraorbital region, often associated with buphthalmos or glaucoma; (2) convulsions, usually contralateral to the side of the naevus; (3) typical intracranial calcification, becoming radiologically visible after infancy; (4) some degree of mental subnormality in the majority of the patients; and (5) hemiparesis and homonymous hemianopia contralateral to the brain lesion in a substantial proportion of cases. Atypical cases or forme fruste varieties not displaying all features are well known (Alexander, 1972) and there is probably no reason why these should be excluded by definition from the Sturge-Weber syndrome when the basic pathology-namely, leptomeningeal angiomatosis-is present.

The radiological hallmark of the syndrome is double-contoured curvilinear calcification following a gyral pattern (Alexander and Norman, 1960), becoming radiologically recognizable later in childhood and involving most frequently the occipital and parietal area. This classical pattern seems to be pathognomonic for Sturge-Weber

\footnotetext{
${ }^{1}$ Address for correspondence: E. B., Children's Hospital, Steinwiesstrasse 75, CH-8032 Zurich, Switzerland.

(Accepted 22 December 1975.)
}

syndrome. The appearances could perhaps most easily be confused with those seen in ossifying meningoencephalopathy, but a clear distinction on radiological grounds is possible (Wackenheim, 1973).

Occasionally bilateral intracranial calcification occurs in the Sturge-Weber syndrome, but this is not referred to in any of the widely used textbooks of radiology, neurology, or paediatrics. Therefore, we feel justified in reporting four children with bilateral calcification who have been identified at The Hospital for Sick Children in the past four years.

\section{CASE MATERIAL}

During the past 21 years there have been 22 children referred to this hospital with facial naevi and leptomeningeal angiomatosis, of whom seven have been recently reviewed. Four other children had all the features of Sturge-Weber syndrome including typical intracranial calcification except that they had no trace of cutaneous abnormality. Cortical calcification was present in 21 out of 26 patients.

Information from four cases with bilateral intracranial calcification is presented in Table 1 . It is notable that three children became microcephalic, initially having had head circumferences well within the normal range. Cases 3 and 4 have not achieved any motor or intellectual skills for which their lack of vision cannot account alone, whilst their neurophysiological investigations-initially normal, later absent visual evoked response (VER)—suggest that their blindness is cortical. 


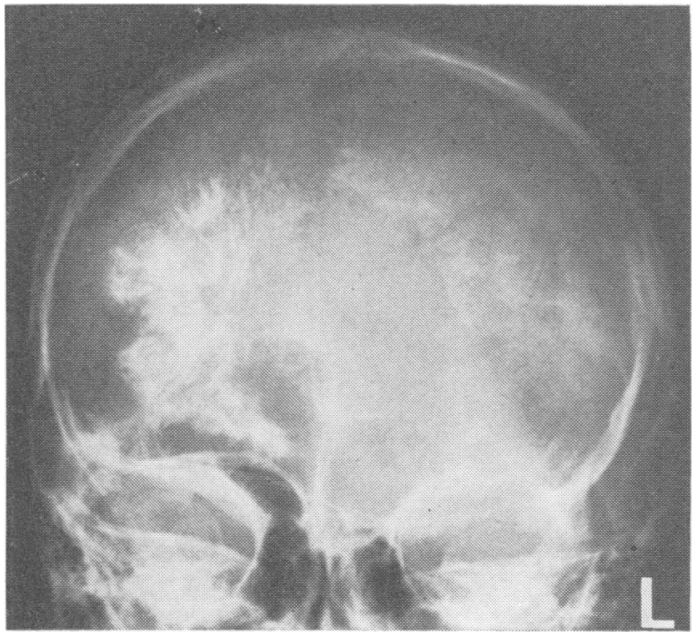

FIG. 1 Case 1. AP skull radiograph showing bilateral calcification, more extensive on the right. Note right hemiatrophy of the skull.

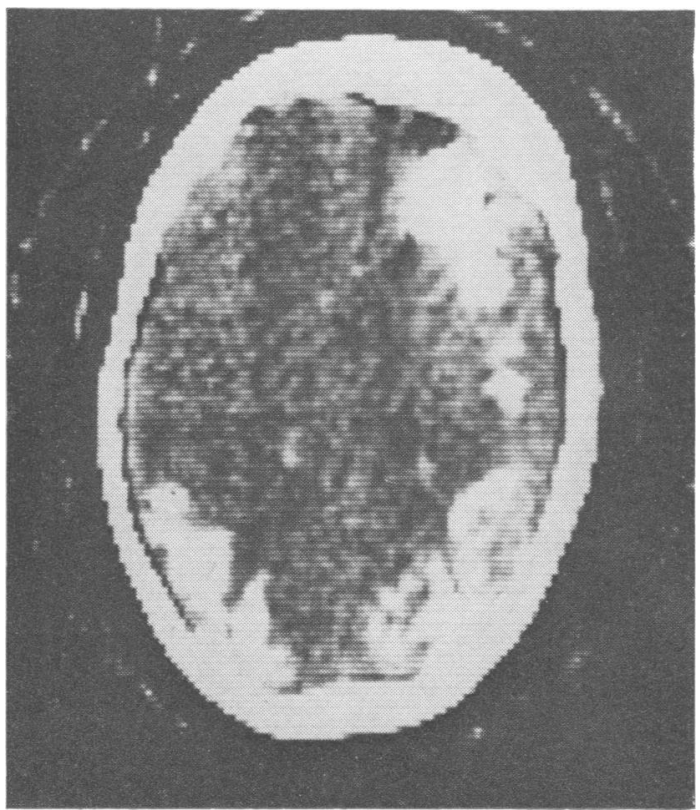

FIG. 2 Case 1. EMI scan. Extensive calcification in right hemisphere and in left parieto-occipital region.

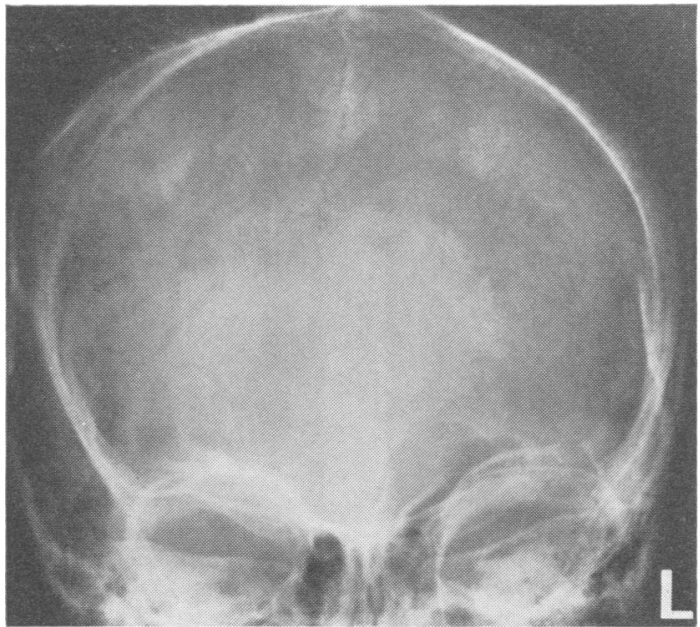

FIG. 3. Case 2. AP skull radiograph. Bilateral faint typical calcification seen above the right and superimposed upon the left lambdoid suture. There is left hemiatrophy of the skull. 


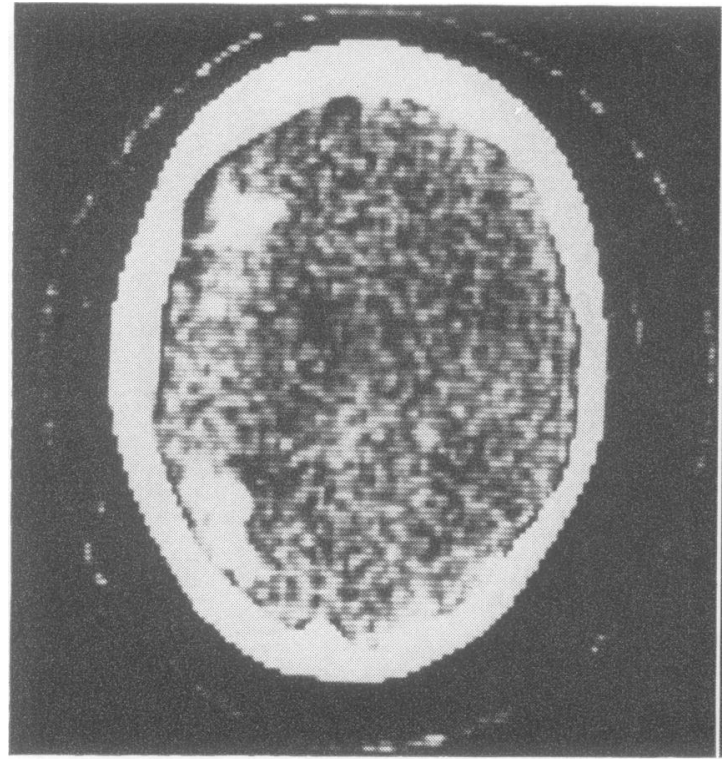

(a)

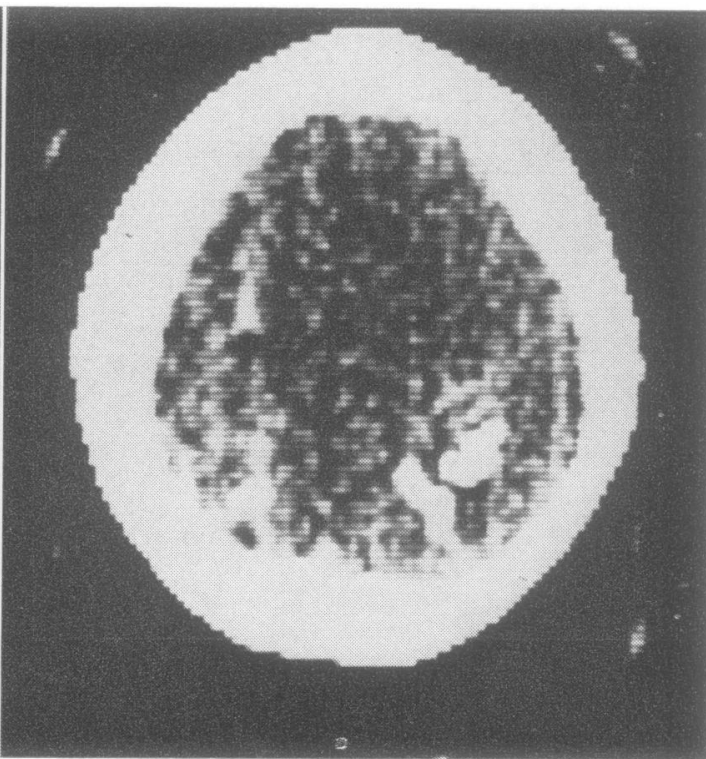

(b)

FIG. 4 Case 2. EMI scan. (a) Calcification in a widespread area of the left hemisphere. (b) A higher section $\stackrel{\overrightarrow{\mathrm{Q}}}{\mathrm{\Omega}}$ 음 reveals similar calcification in the right parieto-occipital region.

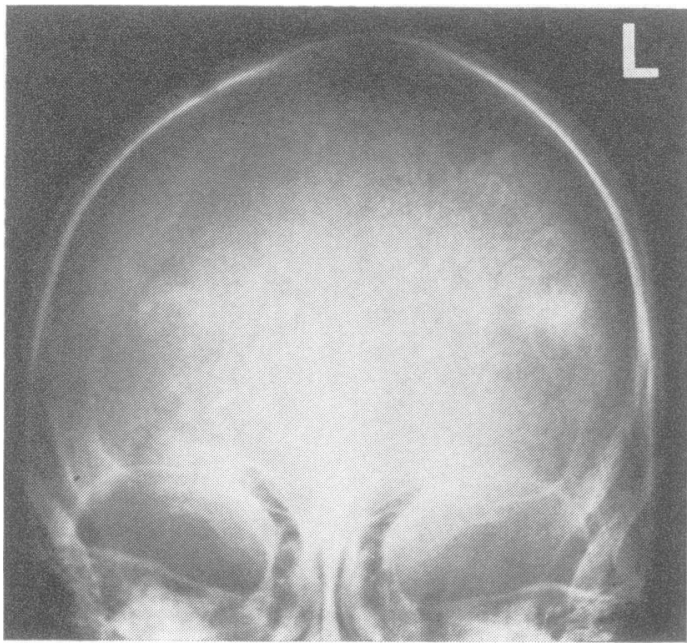

FIG. 5 Case 3. AP skull radiograph. Marked bilateral gyriform calcification.

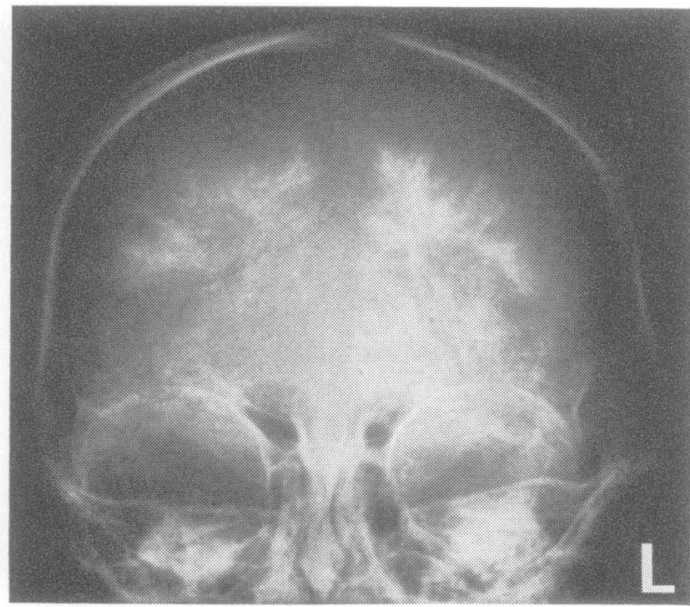

FIG. 6 Case 4. AP skull radiograph. Dense curvilinear calcification in both hemispheres, more marked on the left. 


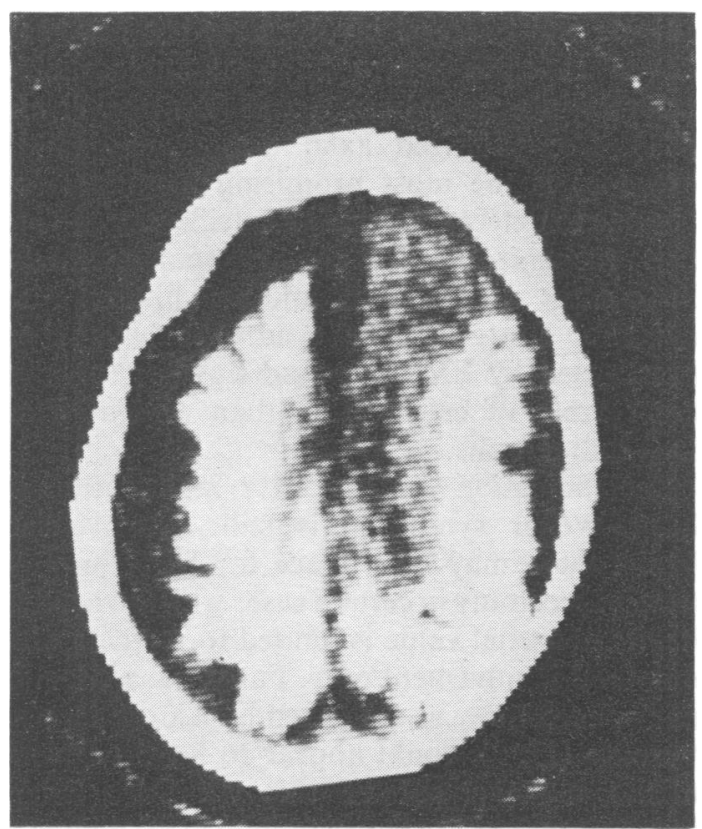

FIG. 7 Case 4. EMI scan. The densely calcified left hemisphere is very atrophic and the cortical gyri and sulci are well outlined. The right hemisphere is less involved in the frontal region. The gap between skull vault and hemispheres represents, presumably, a widened subarachnoid space.

\section{DISCUSSION}

To our knowledge only 17 cases of Sturge-Weber syndrome have so far been reported with evidence of bilateral intracranial calcification (Table 2). In twelve cases a bilateral facial naevus was encountered while two patients had no port-wine stain at all. Apart from one possible exception (Parnitzke's case 2, 1956) all patients of whom details are available had epilepsy and some degree of mental subnormality. Bilateral calcification was demonstrable in eight cases before the age of ten years. Cortical blindness, as seen in our cases 3 and 4, has so far only been mentioned in one other child (Collignon and Carlier, 1974). Some cases have been misleadingly referred to as bilateral (Bock, 1950; Ishiguro et al., 1963; Tiurikov, 1971), but they have no evidence of bilateral hemispheric involvement.

The frequency of bilateral intracranial calcification occurring in Sturge-Weber syndrome is not known, and it is difficult to estimate it from the literature. A number of reports select patients who underwent neurosurgical procedures and cases with bilateral calcification are very likely a priori excluded; in other series bilateral hemisphere involvement may be excluded by definition, and in other reports many patients

TABLE 2

REPORTED CASES OF STURGE-WEBER SYNDROME WITH BILATERAL INTRACRANIAL CALCIFICATION

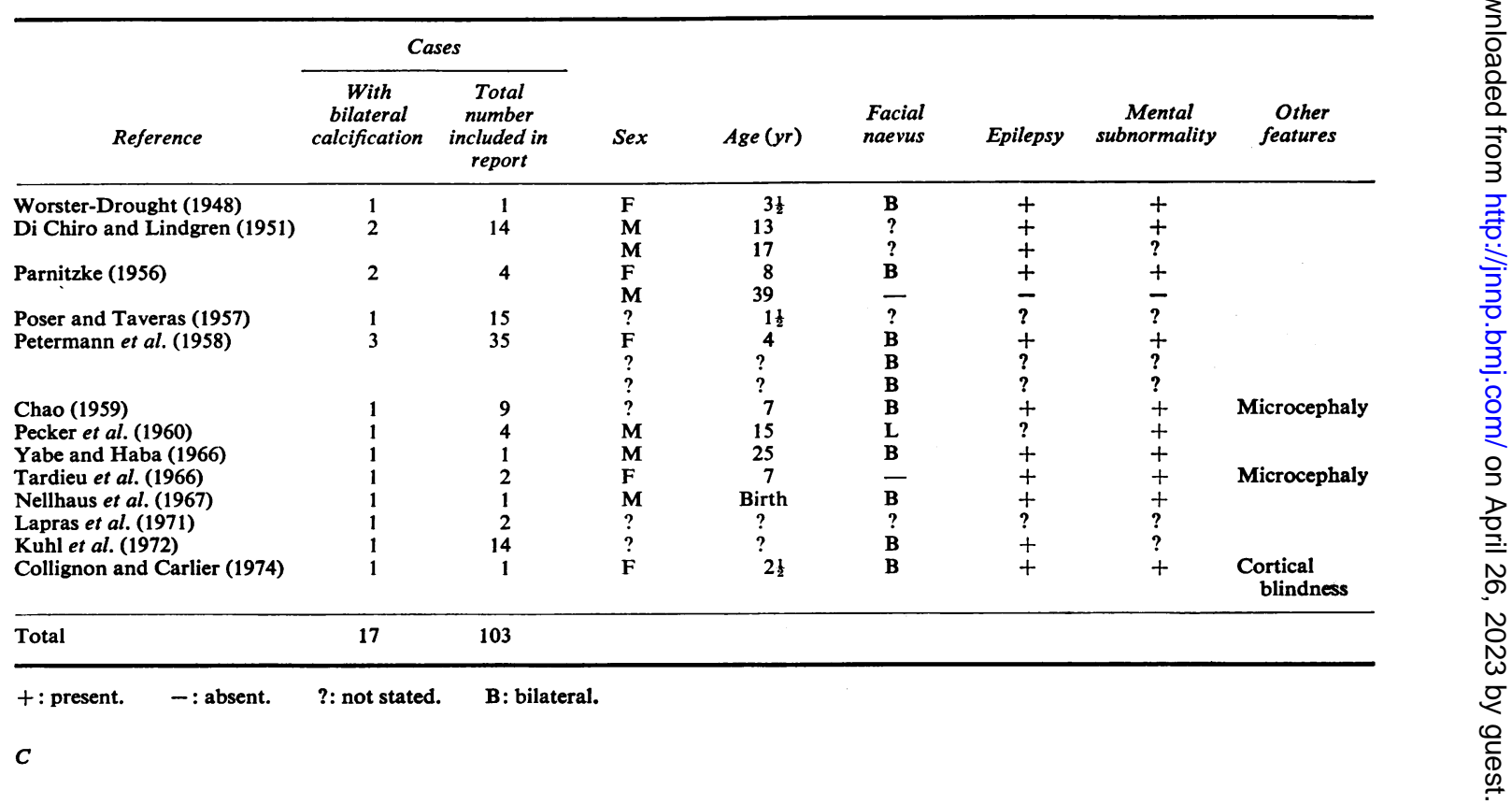


were too young to show calcification and probably a considerable proportion of those children who were not operated on may never have had repeat skull radiographs. The 17 previously described patients (Table 2) represent 17 per cent of the total number of cases included in these reports. It could be argued that this is an over-estimate since four out of 13 reports presented only a single case, but it is interesting that 15 per cent (4 out of 26) of the children with Sturge-Weber syndrome seen at this hospital had both hemispheres affected. Because of bias in the selection of patients referred to The Hospital for Sick Children it is debatable whether this reflects accurately the prevalence of bilateral hemisphere involvement. We think, however, it is unlikely that selection operates significantly to allow overrepresentation of bilateral as distinct from unilateral involvement. Indeed the four described children may underestimate bilateral leptomeningeal angiomatosis in our series since there are two other patients with oligophrenia from early infancy who could not be reviewed.

Is it possible to suspect bilateral hemisphere involvement on clinical grounds? Although our experience is limited it seems to us that severe subnormality which is already obvious in the first year of life may suggest widespread cortical disease. Clearly the distribution of the facial naevus is of no help since a bilateral port-wine stain was present in a third of all our referred cases with Sturge-Weber syndrome. The head circumference in the three children displaying later microcephaly was within normal limits in the first year of life, suggesting that this is not of prognostic value at an early stage. However, a fall-off in head circumference beyond infancy may be a valuable indicator since microcephaly is uncommon in Sturge-Weber syndrome. In our limited experience the EEG at an early stage is not a sufficiently reliable guide as far as prediction of bilateral hemisphere involvement is concerned and in later childhood bilateral EEG changes (excess of slow components, low amplitude over some areas) are not uncommon in patients with presumably strictly unilateral leptomeningeal angiomatosis.

Plain skull radiographs have so far been the most helpful investigation. The value of angiography in this respect is doubtful since normal studies have been reported in a number of patients and bilateral involvement has not been proved in cases where bilateral angiographic abnormalities have been found (Bentson et al., 1971). Computerized axial tomography (EMI scanning) is the most promising method since it is able to detect intracranial calcification before it is recognizable by conventional methods. Three cases with bilateral and six children with unilateral Sturge-Weber syndrome have been investigated by EMI scan and this has revealed larger areas of calcification than evident from skull radiographs.

The indication for operative intervention in Sturge-Weber syndrome is still controversial. Whilst there may be a place for lobectomy or hemispherectomy in certain cases with intractable fits, its potential value is limited to patients with unilateral involvement only. Early 'prophylactic' hemispherectomy as suggested by Alexander and Norman (1960) would appear to have no place in the management of this condition when uncertainty about the possibility of bilateral involvement exists, especially if the more extensive leptomeningeal angiomatosis is as frequent as our figures suggest.

We are grateful to Prof. G. Du Boulay, Department of Radiology at the National Hospital for Nervous Diseases, for his permission to include illustrations of EMI scans. We thank the consultants of The Hospital for Sick Children for allowing us to study cases under their care and Dr G. Pampiglione and Dr A. Harden for performing the electrophysiological investigations. E. B. was supported by a grant from the Swiss National Foundation.

\section{REFERENCES}

Alexander, G. L. (1972). Sturge-Weber syndrome. In Handbook of Clinical Neurology, pp. 223-240, vol. 14. Edited by P. J. Vinken and G. W. Bruyn. NorthHolland: Amsterdam.

Alexander, G. L., and Norman, R. M. (1960). The SturgeWeber Syndrome. Wright: Bristol.

Bentson, J. R., Wilson, G. H., and Newton, G. H. (1971). Central venous drainage pattern of the Sturge-Weber syndrome. Radiology, 101, 111-118.

Bock, R. H. (1950). A case of bilateral Sturge-Weber syndrome. American Journal of Ophthalmology, 33, 1121-1127.

Chao, D. (1959). Congenital neurocutaneous syndromes of childhood. III Sturge-Weber disease. Journal of Pediatrics, 55, 635-649. 
Collignon, J., and Carlier, G. (1974). Forme bilatérale de la maladie de Sturge-Weber avec anomalie rare du drainage veineux. Acta Neurologica Belgica, 74, 81-93.

Di Chiro, G., and Lindgren, E. (1951). Radiographic findings in 14 cases of Sturge-Weber syndrome. Acta Radiologica. Diagnosis, 35, 387-399.

Ishiguro, K., Sato, H., and Ishigami, H. (1963). A case of bilateral Sturge-Weber's syndrome with unusual anomalies. Japanese Journal of Clinical Ophthalmology, 17, 1037-1047.

Kuhl, E. D., Bevilacqua, J. E., Mishkin, M. M., and Saners, T. P. (1972). The brain scan in Sturge-Weber syndrome. Radiology, 103, 621-626.

Lapras, C., Dechaume, J.-P., Revol, M., Nicolas A., and Deruty, R. (1971). A propos du traitement de la maladie de Sturge-Weber chez l'enfant. Pédiatrie, 26, 789.

Nellhaus, G., Haberland, C., and Hill, B. J. (1967). SturgeWeber disease with bilateral intracranial calcification at birth and unusual pathologic findings. Acta Neurologica Scandinavica, 43, 314-347.

Parnitzke, K. H. (1956). Symptomwert und Symptomverteilung bei der Sturge-Weberschen Krankheit. Zentralblatt für Neurochirurgie, 16, 92-109.

Pecker, J., Javalet, A., and Stabert, Ch. (1960). Aspects radiologique dans quatre cas d'angiomatose encéphalotrigeminée. Journal de Radiologie, d'Electrologie et de Médicine Nucléaire, 41, 487-490.
Petermann, A. F., Hayles, A. B., Dockerty, M. B., and Love, J. G. (1958). Encephalotrigeminal angiomatosis (Sturge-Weber disease). Clinical study of thirty-five cases. Journal of the American Medical Association, 167, 2169-2176.

Poser, C. M., and Taveras, J. M. (1957). Cerebral angiography in encephalo-trigeminal angiomatosis. Radio$\log y, 68,327-336$.

Tardieu, G., Metzger, J., and Brusset, B. (1966). Calcifications intra-crânniennes de type Sturge-Weber sans angiome cutané chez un infirme moteur cérébral. Revue Neurologique, 114, 466-469.

Tiurikov, A. (1971). Bilateral encephalo-trigeminal angiomatosis in association with glaucoma and affection of the hearing organ (in Russian). Oftalmologicheskii Zhurnal (Odessa), 26, 387-388.

Wackenheim, A. (1973). Meningoencéphalopathie ossifiante. Journal Belge de Radiologie, 56, 373-375.

Worster-Drought, C. (1948). Sturge-Kalischer-Weber syndrome of bilateral distribution. British Medical Journal, 2, 414-416.

Yabe, T., and Haba, R. (1966). A case of bilateral SturgeWeber syndrome. Brain and Nerve (Tokyo), 18, 11371142 . 